\title{
Perspectivas da Rodada Uruguai: implicações para o Brasil
}

\section{PAULO NOGUEIRA BATISTA}

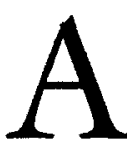

Rodada Uruguai é a oitava de uma série de negociaçōes comerciais multilaterais, um tipo de negociação coletiva muito especial que somente se viabilizou, em 1947, quando entrou em vigor o Acordo Geral de Tarifas e Comércio-GATT. Lançada em Punta del Este, em setembro de 1986, após quatro anos de discussóes e preparaçáo, a Rodada náo pôde ser concluída em Bruxelas, em dezembro de 1991, tendo sido prorrogada por mais dois anos.

Para avaliar a Rodada Uruguai, é importante levar em conta o contexto econômico em que se situa, bem como o quadro legal e institucional em que se processa. Vale muito a pena, ainda que perfunctoriamente, buscar entender o que é o GATT e o que ocorreu nas Rodadas anteriores à que se encontra em fase de conclusăo.

A expressão GATT, do inglês General Agreement on Tariffs and Trade, significa em português não só o Acordo Geral de Tarifas e Comércio mas também o foro em que se conduzem negociaçóes comerciais multilaterais do tipo da Rodada Uruguai. Em inglês, a distinção se estabelece com facilidade: The GATT é o Acordo Geral; GATT é o foro. Neste texto, a expressão Acordo Geral se refere ao primeiro caso; e a sigla GATT, ao segundo.

Como sistema normativo, o Acordo Geral repousa, em essência, sobre uma obrigação multilateral de não discriminar. Em primeiro lugar, pela extensão a todos os parceiros, em bases incondicionais, do mesmo tratamento na importação de mercadorias; e, subseqüentemente, pela igualdade de tratamento dado ao produto importado desta forma e aquele dispensado ao produto nacional. Em outras palavras, a observância, na fronteira, do princípio MFN da Nafão-Mais-Favorecida e, dentro do país, do princípio do tratamento nacional.

Essa preocupação dominante com o multilateralismo não-discriminatório constitui, no pós-guerra, a resposta da comunidade internacional às preferências coloniais $e$, sobretudo, ao bilateralismo discrimi- 
natório dos anos trinta, fonte e expressão de acirradas disputas comerciais que agravaram as fortes tensóes políticas da época.

No Acordo Geral, portanto, a liberalizaçáo comercial aparece mais como um objetivo do que como uma obrigação. A não-discriminação, especialmente sob a forma incondicional pela qual se acha consubstanciada na cláusula MFN, está no âmago do sistema multilateral de comércio do pós-guerra. A liberalização, isto é, a reduçăo de obstáculos ao comércio, não é, nos termos do Acordo Geral, um objetivo em si mesmo, a se realizar pela via de medidas unilaterais; é meta a se alcançar coletivamente, através de negociaçóes multilaterais baseadas em reciprocidade e vantagens mútuas.

O Acordo Geral admite como legítimo, aliás, o recurso a tarifas sobre importaçōes, proibindo apenas as restriçóes quantitativas. Do ponto de vista do GATT, fair trade pode, por conseguinte, ser definido como o comércio náo-discriminatório e livre de restrições quantitativas.

O Acordo Geral não se inspira, pois, na concepçăo clássica de livre comércio, que coloca a liberalizaçáo como regra e objetivo máximos, como a forma ideal para alocaçáo de recursos em escala mundial a realizar-se pela exploração das vantagens comparativas naturais de cada país. $\mathrm{Na}$ realidade, o Acordo Geral foi a alternativa que os EUA encontraram para contornar a pouca disposiçăo do seu Congresso de concordar com algo bem mais amplo: a instituição de uma Organização Internacional de Comércio, prevista na Carta de Havana, de 1948. O Acordo Geral consiste, essencialmente, num quadro jurídico multilateral construído a partir de um capítulo da citada Carta, que trata do comércio de mercadorias - dentro do qual se deveriam processar as negociaçóes de concessóes tarifárias com base na multilateralizaçăo da cláusula da Nação-Mais-Favorecida.

Através das negociaçōes multilaterais que se sucederam em seu âmbito, o GATT foi passando por uma gradual evoluçăo que configura a existência hoje de um sistema que já ultrapassou o Acordo Geral, em. bora este permaneça como seu núcleo. Desde a primeira Rodada, em 1948, até o Kennedy Round, que durou de 1963 a 1967, as negociaçōes se limitavam essencialmente a uma liberalizaçáo do comércio de manufaturas e eram efetuadas através de reduçóes tarifárias, caso a caso, à base da reciprocidade, entre fornecedor e comprador principais. $O$ caráter multilateral do processo era assegurado pela simultaneidade das negociaçōes bilaterais, pela observância das mesmas regras de negociação e, acima de tudo, pela multilateralizaçáo dos resultados obtidos bilateralmente, através da sua extensáo a terceiros países pela aplicaçáo 
incondicional da cláusula MFN, de tratamento para todos igual ao melhor tratamento concedido a qualquer Naçáo.

As primeiras modificaçóes importantes na sistemática das Rodadas Multilaterais se verificariam na Rodada Kennedy, quando as reduçóes tarifárias passaram a se fazer com base num corte linear sobre todas as posiçóes tarifárias, excetuadas apenas as que fossem expressamente excluídas do processo. $O$ novo procedimento, além de reforçar a natureza multilateral das negociaçōes, acelerou substancialmente a liberalizaçăo tarifária. O Kennedy Round introduziu, contudo, outra grande novidade que viria enfraquecer o sistema multilateral: a negociaçáo, entre os países desenvolvidos, de um Código Anti-Dumping cujas cláusulas seriam aplicadas apenas aos seus signatários. Modificava-se, assim, sem uma emenda formal do Acordo Geral, o seu princípio fundamental de aplicaçáo incondicional da cláusula de maior favor.

A Rodada Tóquio, lançada em 1973 e concluída em 1979, se destacaria das anteriores pela maior importância que adquiririam as questóes normativas e, especificamente, pelo uso abusivo que se fez, para dispor sobre esses problemas, da técnica de negociação de Códigos, como processo facilitado de revisão do Acordo Geral. Distingue-se entre os numerosos Códigos então negociados o de Subsídios, o qual, embora restrito a produtos manufaturados, introduziu a importante exigência de teste material para comprovação de dano capaz de justificar a aplicação de direitos compensatórios.

Com o recurso aos Códigos como instrumento de normatização, começou a esboçar-se um GATT à deux vitesses, isto é, um GATT mais rápido para os países desenvolvidos já em condiçōes de assumir novas obrigaçóes, e outro mais lento para os países em desenvolvimento despreparados para assumi-las. O GATT, como sistema normativo, deixou de ser apenas o Acordo Geral para abranger também os Códigos.

\section{O contexto econômico}

Năo obstante as diferenças que se evidenciaram de uma para outra Rodada, todas registram grandes linhas de continuidade cuja evocação pode ajudar a entender melhor ás características da Rodada Uruguai ora em curso. São três essas linhas: (a) a concentraçáo sobre problemas tarifários; (b) o foco sobre produtos industriais; e (c) a virtual marginalização dos países em desenvolvimento.

O grande sucesso do GATT na liberalização comercial, ao longo de três décadas, ficou, assim, por definiçáo, restrito à reduçáo das bar- 
reiras tarifárias dos países desenvolvidos para produtos manufaturados, o que se fez, vale ressaltar, a níveis muito baixos - hoje em torno de $5 \%$ em média - e sob a forma de posiçóes consolidadas no GATT, isto é, insuscetíveis de revogação unilateral sem compensação em outro produto.

A marginalizaçáo dos países em desenvolvimento decorreu da própria concepçáo que inspirara a elaboração do Acordo Geral, como instrumento de regulação de comércio entre países já industrializados, com suficiente poder de barganha para obter, pela reciprocidade, melhores condiçóes de acesso para seus produtos de exportação. Para os países subdesenvolvidos dependentes primordialmente da exportação de poucos produtos primários - náo sujeitos a tarifas, por conveniência dos próprios importadores desenvolvidos em só taxar os produtos elaborados - o GATT náo era atraente. Muito mais importante era lutar, fora do GATT, por acordos de estabilizaçăo do preço de suas commodities.

O fato de não serem os subdesenvolvidos competidores na área industrial fez com que não lhes fosse cobrada, nas sucessivas rodadas de negociações, reciprocidade pelo acesso que tinham teoricamente, graças à clausula MFN, às reduçōes tarifárias feitas pelos países desenvolvidos. $\mathrm{Na}$ realidade, os países em desenvolvimento se concentrariam, nas Rodadas do GATT, a solicitar que lhes fosse concedido um tratamento especial e mais favorável, princípio que a UNCTAD proclamou e o GATT acabou incorporando em sua Parte IV. Em nome desse princípio, os países em desenvolvimento reivindicavam acesso aos mercados de manufaturas dos países desenvolvidos, em termos não apenas não-recíprocos, mas também preferenciais. A reivindicação terceiro-mundista foi finalmente atendida, no início dos anos setenta, no contexto do Sistema Geral de Preferências da UNCTAD, através, no entanto, de esquemas individualmente outorgados pelos países desenvolvidos, de forma voluntária e provisória, a todos os países em desenvolvimento.

O inegável êxito do GATT em reduzir tarifas foi, contudo, fortemente comprometido por três fatores. Em primeiro lugar, pela corrosăo do princípio fundamental do Acordo Geral, o da não-discriminação entre os parceiros comerciais; por outro lado, pelo aumento substancial das barreiras não-tarifárias; e, finalmente, pela incapacidade do GATT de submeter o comércio de produtos agrícolas a suas disciplinas. Os três problemas se entrelaçam em boa proporçăo à medida que a prática da discriminaçáo ocorre em forte grau nos obstáculos náo-tarifários e que estes afetam substancialmente os produtos agrícolas. 
O surgimento desses fatores negativos está muito vinculado, por um lado, aos processos de integração econômica na Europa Ocidental e, por outro, à emergência de novos competidores no comércio internacional, principalmente o Japão e a seguir os chamados Newly Industrialized Countries (NICs), isto é, países de industrializaçăo recente, entre os quais o Brasil.

Os processos de integração econômica constituem, por definição, uma exceção à cláusula MFN, desvio que o Acordo Geral admite desde que incluam em prazo certo a formação de uma tarifa externa comum a nível médio náo superior ao prevalecente nas tarifas individuais anteriores e que seus efeitos sejam de criação de comércio (trade-creating) e náo substitutivos de comércio (trade diverting). A integraçáo comunitária teve impacto modesto na área de produtos industrializados $\mathrm{em}$ conseqüência do próprio êxito do GATT em reduzir tarifas, diminuindo automaticamente a margem de preferência intracomunitária. Sua principal consequiência se localizaria na área agrícola onde, através da Política Agrícola Comum (PAC), se estabeleceram fortes esquemas protecionistas. Desses esquemas resultaram não só o fechamento do mercado comunitário à importaçáo de grande número de produtos agrícolas, mas ainda a sua própria transformação, graças a vultosos subsídios, em grande exportador de produtos agrícolas, sobretudo temperados.

Anote-se, todavia, que o insucesso do GATT em disciplinar a área agrícola tem raízes mais profundas que a política agrícola comum da CEE. As regras do Acordo Geral sempre foram, desde o início, por influência dos próprios EUA, menos precisas e abrangentes que as relativas a manufaturas. Graças à chamada Grandfather clause, introduzida por proposta dos.EUA no Protocolo que colocou em vigor o Acordo Geral, essas regras limitadas não eram aplicáveis, de qualquer modo, a restriçóes baseadas em legislaçōes nacionais anteriores ao Acordo Geral. Para pôr em prática as novas restriçóes de mercado que advieram da adoçáo do Agricultural Adjustment Act de 1955, os EUA foram além, entretanto. Obtiveram do GATT, no mesmo ano, uma dispensa (maiver), até hoje vigente, de suas obrigações, pela qual continuaram em liberdade para proteger sua agricultura, mediante legislaçáo posterior ao Protocolo de Adesáo.

A capacitação industrial dos NICs se deu em escala apreciável, e em alguns casos predominantemente, graças a políticas de substituiçăo de importaçóes às quais seguiram-se outras de promoçáo de exportaçóes, apoiadas em proporção expressiva por capitais estrangeiros de risco e numa estrutura protecionista do mercado interno. Os investimentos estrangeiros foram muito importantes na transformação da estrutura 
econômica de alguns países em desenvolvimento em NICs, não somente pelo reforço de sua capacidade de poupança e de investimento, mas também pela tecnologia de produção que lhes foi transferida através de suas subsidiárias ou por licenciamento de firmas locais. Ambos elementos, associados a um baixo custo de máo-de-obra, ensejariam a criaçăo de um parque industrial competitivo tanto na área de bens de consumo duráveis quanto na de bens de capital e, inclusive, de alta tecnologia.

A penetração dos NICs nos mercados desenvolvidos de produtos manufaturados foi facilitada em razáo do êxito obtido pelos países de industrialização mais antiga na redução entre si das barreiras tarifárias sobre produtos industriais. Pela cláusula MFN, como já vimos, os NICs se beneficiariam de uma extensão automática dessas reduçóes sem terem de oferecer contrapartidas nos próprios mercados. Nestes as barreiras tárifárias seriam mantidas elevadas como forma até mesmo de poder atrair, pela reserva de mercado, os investimentos estrangeiros oriundos dos países desenvolvidos.

O recurso, por parte dos EUA e da CEE, a barreiras não-tarifárias para fazer frente à maior competitividade industrial do Japão e dos NICs constitui a violação mais flagrante das regras fundamentais do Acordo Geral, além de anular o valor dos compromissos específicos de liberalização tarifárias assumidos nas Rodadas do GATT. O caso típico dessa tendência neoprotecionista sáo as restrições impostas ao comércio de têxteis. Lançando mão de seu peso econômico e político, os EUA e a Europa Ocidental conseguiram colocar as medidas protecionistas de suas indústrias crepusculares sob o amparo de acordos plurilaterais. Começando com o Long-Term Arrangement in Cotton Textiles, de 1962, estamos hoje com o Multi-Fiber Arrangement, de 1974, sucessivamente prorrogado e sob cuja égide se negociam os acordos bilaterais de quotas. Uma longa história, portanto, de protecionismo institucionalizado que já dura trinta anos, tempo mais do que suficiente para qualquer programa de ajuste estrutural das economias européia e norte-americana nesse setor.

Quotas, quotas-tarifárias, Orderly Market Arrangements (OMAs), Voluntary Export Restraints (VERs), o recurso abusivo a salvaguardas comerciais ilegitimamente invocadas, tudo isso constitui hoje uma verdadeira parafernália de restriçōes que afetam sensivelmente as exportaçóes de manufaturas dos NICs para os países desenvolvidos, atingindo parcela considerável de seu comércio.

A reação dos países de industrialização antiga à competição dos 
países de industrialização recente não se limitou à imposição de obstáculos às respectivas exportaçóes. A abertura dos mercados dos próprios NICs passaria gradualmente a constituir uma meta dos países desenvolvidos. Na visão destes países, a abertura dos mercados dos NICs deveria ser feita de forma unilateral, sem qualquer nova concessão dos desenvolvidos; ou seja, como uma espécie de pagamento com atraso (delayed payment) pelo acesso MFN do qual os países subdesenvolvidos se vinham beneficiando, nos mercados desenvolvidos, como free-riders isto é, como caronas Através da graduation, os NICs deixariam de fazer jus ao tratamento especial e diferenciado reconhecido aos países em desenvolvimento na Parte IV do GATT.

A política de graduation se implantou mais rapidamente no campo financeiro do que no comercial. Países como o Brasil, desde os anos setenta, perderam o direito de se beneficiar de fluxos financeiros concessionais nas agências governamentais e nos órgãos multilaterais de financiamento. A partir da crise do petróleo, viram-se, iñclusive, impelidos a buscar petrodólares em bases estritamente comerciais, junto aos bancos privados, não só para financiar projetos, mas ainda para cobrir necessidades de Balanço de Pagamentos.

\section{A rodada Uruguai: modernização ou retrocesso?}

A política de forçar a graduation dos NICs no plano comercial começou a se materializar com a exclusão progressiva desses países dos benefícios dos esquemas de preferências gerais não-recíprocas - o SGP, outorgado, no quadro da UNCTAD, unilateral e individualmente por cada um dos países desenvolvidos ao conjunto dos países em desenvolvimento. $O$ tratamento discriminatório se faz sentir também nas crescentes medidas protecionistas que adotam os desenvolvidos contra os subdesenvolvidos. Os NICs, pela incapacidade de retaliar, sofrem tratamento muito mais duro do que outros fornecedores desenvolvidos.

Nas discussóes sobre o lançamento da Rodada Uruguai, no início dos anos oitenta, a tese da graduação se torna mais nítida e adquire realmente contornos mais amplos. Fica evidente nas justificativas norteamericanas para uma nova Rodada que esta não seria, como as sete anteriores, uma negociação entre países desenvolvidos. A Rodada teria que incluir como parceiros necessários os países em vias de desenvolvimento de industrializaçáo recente.

Mas náo fica nisso o caráter inovador da Rodada Uruguai. Nela se introduz, por insistente proposta dos EUA, uma concepção mais ampla de comércio pela qual o Acordo Geral passaria a abarcar, como a Carta 
de Havana pretendera, não apenas comércio de bens, mas também o de serviços, propriedade intelectual e investimentos. Sobre essas bases abrangentes, pretende-se muito mais do que simplesmente liberalizar comércio, como nas rodadas anteriores. Pretende-se, desta vez, a elaboração de novas regras que dão à Rodada Uruguai uma dimensáo e um significado todo especial. Para assegurar seu lançamento com essa abrangência, os EUA chegaram inclusive a ameaçar com um eventual desengajamento do regime multilateral de comércio, dando mesmo alguns passos ambíguos nessa direção com a decisão de assinar um acordo preferencial com o Canadá, agora estendido ao México, cuja execução poderá se fazer de forma a comprometer os objetivos do GATT.

A Rodada Uruguai tem, assim, duas grandes vertentes: uma no sentido Norte-Norte relacionada com o contencioso entre os EUA e a CEE a respeito dos subsídios agrícolas; outra, no sentido Norte-Sul em que se evidencia, sob a liderança dos EUA, o propósito de integrar os países em desenvolvimento numa economia mundial reorganizada de forma a preservar as vantagens competitivas de que goza o mundo desenvolvido em termos de capital e, sobretudo, de tecnologia.

A reversão do processo de liberalizaçáo do comércio de manufaturas coincidiria com a intensificaçáo da competiçăo entre EUA e CEE na área de produtos agrícolas temperados, gerando fortes tensóes para o sistema multilateral de comércio. A crise se torna aguda com a adoção pelos EUA de legislação de comércio exterior francamente conflitante quer com as normas do Acordo Geral quer com os compromissos específicos de liberalizaçáo assumidos sob sua égide. E se amplia pelo acirramento do contencioso comercial entre os EUA e o Japáo e pelo caráter discriminatório assumido pelo protecionismo das grandes potências comerciais.

A Rodada Uruguai foi lançada, pois, em circunstâncias e com motivaçóes bem diversas dos rounds que a precederam. Para o Governo dos EUA, seu principal promotor, trata-se não só de buscar remover as causas estruturais do contencioso agrícola com a CEE - os subsídios que sobrecarregam os respectivos orçamentos - mas também de conter, pela via multilateral, a crescente penetração comercial dos NICs.

Ao invés, contudo, de se esforçar para readquirir competitividade através do ajustamento da própria economia, os EUA tentam ajustar o sistema multilateral às conveniências norte-americanas mais imediatas. Buscam, assim, obter a homologação internacional para as regras unilaterais de proteção introduzidas na legislação de comércio dos Estados 
Unidos, transformando-as em regras multilaterais, às quais, na prática, só países com o poderio dos EUA poderăo recorrer.

Na Rodada Uruguai, os países em desenvolvimento - em especial os NICs - passaram, portanto, a ser objeto de fortes demandas. Estão sendo solicitados não só a abrirem-se unilateralmente mas a fazêlo de um só golpe. Sáo instados a renunciar ao conceito tradicional de induistria nascente e, mesmo no caso daqueles cujas moedas continuam inconversíveis, a aceitar menos autonomia na adoção de medidas comerciais de proteçáo do Balanço de Pagamentos.

O desarmamento comercial unilateral passou a ser condição de fato da estratégia estabelecida pelos Governos dos países credores, e pelas instituições multilaterais de financiamento, para a renegociação da dívida externa dos países em desenvolvimento. O FMI e o Banco Mundial vêm prestando, assim, todo apoio tanto à tese da abertura unilateral das economias dos países devedores quanto ao conceito abrangente de comércio propugnado pelos EUA na Rodada Uruguai. O Banco Mundial, em estudo específico, chega a recomendar aos países em desenvolvimento, como o Brasil, que concedam, na Rodada Uruguai, prioridade às questóes agrícolas em detrimento das industriais ou tecnológicas.

Náo obstante a ameaça que a Rodada representa para os interesses de industrialização e diversificação econômica dos países subdesenvolvidos, a resposta desses países tem deixado muito a desejar. Quando não insistem numa postura terceiro-mundista tradicional de pedido de favores sob a forma eufemística de tratamento especial, aceitam a tese da abertura externa a qualquer preço, aquela que os países desenvolvidos apregoam mas nunca de fato praticaram nem praticam. A única demonstração de compreensão das verdadeiras implicaçóes da nova Rodada foi dada pelo Brasil e pela Índia, por ocasiāo da definiçáo, em Punta del Este, do mandato inicial de negociação em relação aos chamados novos temas. Em aliança com a CEE, conseguiram os dois países: (a) dar à questão de serviços tratamento que náo prejulgava a decisão final sobre a inclusão dos eventuais resultados no sistema do GATT; e (b) circunscrever as negociaçōes sobre propriedade intelectual e sobre investimentos a uma compatibilizaçáo das normas nacionais existentes nessas áreas com as regras do Acordo Geral.

No Mid-term Review da Rodada Uruguai, começado em Montreal ao final de 1988 e concluído em Genebra em abril de 1989, os países em desenvolvimento, inclusive o Brasil, se alinhariam, entretanto, com os EUA não só na questão agrícola, mas igualmente no que se refere aos nopos temas. Aceitou-se então a redefinição dos mandatos acordados em 
Punta del Este para incluir, por exemplo, o estabelecimento através do GATT de novos padrōes de protefăo à propriedade intelectual.

Para constituir uma autêntica e moderna resposta aos novos desafios do comércio mundial, seria de esperar que a Rodada Uruguai se apoiasse, entretanto, numa visáo mais atualizada da forma pela qual efetivamente se processam os fluxos de comércio. Estes se baseiam, cada vez mais, no intercâmbio intra-setorial e intrafirma assim como na ampla circulaçáo de capitais e de tecnologia.

Curiosamente, entretanto, a Rodada está girando em torno da visão anacrônica de livre comércio, tal como concebida, há quase duzentos anos na Inglaterra, ao iniciar-se ali a Revoluçáo Industrial. Nessa visão, cada país, ao buscar maximizar suas pantagens comparativas, deveria fazê-lo com base na premissa da imobilidade internacional dos fatores de produção. Ou seja, que capital, mão-de-obra e tecnologia náo devem ser estimulados a cruzar fronteiras e que só fatores naturais de produção deveriam ser mobilizados. Uma concepção estática das bases da competição internacional, onde os fluxos de comércio seriam intersetoriais, contentando-se uns a produzir matérias-primas e outros manufaturas.

Através de uma definição muito ampla de comércio, abrangente de serviços, de investimentos e de tecnologia, propóem os EUA disciplinas internacionais que implicariam em congelamento das estruturas econômicas de poder, através de obstáculos jurídicos à movimentaçáo transfronteiras de capitais e de tecnologia. Investimentos ou tecnologia suscetíveis de criar capacidade de produçáo substitutiva de importaçóes ou para exportação passarão a ser coibidos, eis que seriam vistos como uma interferência no livre comércio de bens.

A orientação que os países desenvolvidos pretendem impor à Rodada Uruguai privilegia, em última análise, o intercâmbio de mercadorias sob a forma de produtos acabados. Se predominar, como parece provável, ensejará marginalização crescente dos países em desenvolvimento. Estes terăo certamente muito mais dificuldades, pelas novas regras de comércio, de participar das formas mais modernas de intercâmbio intra-setorial, praticadas entre os países desenvolvidos de economia de mercado, em todas as etapas do processo produtivo. Isso seria verdadeiro mesmo em relação aos NICs, países de industrializaçáo recente, visto que náo possuem ainda base tecnológica própria. A prevalecer essa orientaçáo, a economia do mundo se baseará numa nova divisão de trabalho, de forte sabor colonialista. De um lado, países com possibilidades de plena industrialização; de outro, países com perspecti- 
vas, no máximo, de manter seus atuais níveis de industrialização e bem assim países condenados a permanecer como fornecedores de matériasprimas ou produtos agrícolas.

\section{Considerações finais}

Em que consiste, nesse quadro, o éxito da Rodada Uruguai? $\mathrm{O}$ contencioso Norte-Sul já está na prática resolvido, de fato mal resolvido, com a disposição dos países em desenvolvimento de aceitar, no essencial, por via multilateral, bilateral ou mesmo unilateral, as principais demandas dos países desenvolvidos. Resta o contencioso EUA-CEE de cujo equacionamento depende agora, exclusivamente, o sucesso da Rodada. Em que medida a CEE poderá aceitar as reivindicaçōes norteamericanas de liberalizaçáo do comércio agrícola ou até que ponto os Estados Unidos poderão ter de se declarar atendidos com concessóes comunitárias? Até onde os EUA, para lograrem um máximo resultado na área agrícola, renunciarão ao seu arsenal de medidas unilaterais, através, por exemplo, da subordinação efetiva das leis de comércio exterior daquele país às regras de um GATT transformado em Organizaçáo Mundial de Comércio, como propóe a CEE?

A resistência da CEE - em particular da França - às reivindicações norte-americanas na área agrícola ou a intransigência norteamericana nessas reivindicaçóes poderão levar a um impasse definitivo, isto é, ao não fechamento da Rodada Uruguai. O impasse é hoje possível porquanto a CEE já detém agora, como superpotência econômica, um poder efetivo de veto, à medida que consegue se manter unida; vale dizer, os EUA já não podem mais, como no passado, impor hegemonicamente a sua vontade, embora continuem sempre a poder vetar um resultado que os desagrade.

Mas é tal impasse provável? E o que é mais importante, estaria, nesse caso, realmente ameaçada a sobrevivência do sistema multilateral de comércio, da mesma forma como já ocorreu com o sistema multilateral de pagamentos de Bretton Woods?

Os Estados Unidos, ao desvincularem, nos anos 70, o dólar do ouro, desinteressaram-se certamente da sobrevivência de Bretton Woods, pelo menos no que diz respeito a um dos seus aspectos centrais, as paridades fixas de câmbio. Não está claro porém que poderão se desinteressar da mesma forma do sistema multilateral de comércio. Mesmo numa nova administração democrática, como a que assumirá o poder em janeiro de 1993, mais comprometida com a idéia de uma maior dose de protecionismo para poder reconstruir a economia norte-ameri- 
cana, Washington não poderá abrir mão facilmente das soluçōes multilaterais para o comércio mundial. Estas não são apenas mais compatíveis, por definiçăo, com as aspiraçóes hegemônicas às quais os EUA está longe de ter renunciado; são também mais compativeis com a preservaçáo da segunda grande coluna sobrevivente do sistema multilateral de pagamentos, a conversibilidade das moedas, ainda que a taxas flutuantes.

O mais provável, assim, é que se verifique, ainda que com mais uma prorrogação das negociaçôes, uma composiçáo que permita a ambos os lados desenvolvidos declarar vitória, ou seja, o exito da Rodada Uruguai, tão aguardado pela imprensa internacional. Para os países subdesenvolvidos, esse é um éxito que poderá ter, contudo, um sabor amargo de derrota, transformados que foram em objeto mas náo em sujeito das negociaçóes Uruguai. Terão, por esse motivo, muito mais a pagar do que a receber. Além das novas regras limitativas ao livre fluxo de capitais e de tecnologia - regras que muitos já aceitaram unilateralmente ou em entendimentos bilaterais com os Estados Unidos deverão assumir a obrigação de consolidação, e fazê-lo a níveis substancialmente baixos, da generalidade de suas tarifas aduaneiras. Tudo isso sem a contrapartida de melhoria efetiva de acesso aos mercados dos países desenvolvidos e possivelmente sem a renúncia efetiva destes a medidas unilaterais de proteção.

O Brasil, pela composição diversificada de sua pauta exportadora e de seus mercados externos, pela sua marcada vocaçăo industrial, é um país que tem, certamente, um forte interesse na preservaçáo do sistema multilateral de comércio, o único verdadeiramente compatível com a globalização da economia mundial. Mas é um país que não pode deixar de ter sérias dúvidas sobre se a preservação do multilateralismo comercial deve ser feita à custa para o Brasil de menos acesso a investimentos estrangeiros e, em particular, à tecnologia. Menos ainda pode se dispor a pagar esse preço em troca apenas de uma liberalizaçáo do comércio de produtos agrícolas temperados destinada essencialmente a beneficiar os próprios EUA e a CEE, ao permitir que reduzam os respectivos níveis de subsídios sem chegar a comprometer a capacidade de competiçáo entre si e com terceiros.

Para poder realmente negociar a contento sua inserçăo internacional, o Brasil terá de aprender muito, a começar por um dimensionamento mais correto de seu poder de barganha, isto é, da sua capacidade de influência, sem subestimar nossas possibilidades e sem superestimar a dos nossos parceiros. Na realidade, perdemos na Rodada Uruguai uma grande oportunidade, posto que ali se discutiam questóes da maior rele- 
vância para o Brasil e que os foros multilaterais oferecem, por definição, maior espaço de manobra para nos garantir uma inserção mundial mais vantajosa. Influímos muito pouco nos rumos da Rodada e nos achamos agora marginalizados, na posição quase de observador, a torcer, discreta e resignadamente, pelo seu éxito, na esperança de que um entendimento entre os EUA e a CEE possa nos ser mais benéfico, ou menos prejudicial, que um desentendimento. O Governo Collor, coerente com sua postura ultraliberal $\mathrm{e}$ de alinhamento automático às teses norteamericanas, já anunciou, por antecipaçăo, a disposição de aderir ao $\mathrm{Pa}$ cote proposto pelo Diretor Geral do GATT, quaisquer que sejam as modificaçóes que resultarem do entendimento entre Estados Unidos e as Comunidades Européias.

É muito importante registrar que os resultados da Rodada Uruguai em todos os terrenos - inclusive nos novos temas de serviços, propriedade intelectual e investimentos estrangeiros - são entendidos como integrantes de um todo indivisível - um single undertaking. Vale dizer, estaremos diante da difícil decisão de aceitar ou recusar a totalidade dos entendimentos alcançados, sem poder escolher, como fizemos na Rodada Tóquio, quais os Códigos que o Brasil subscreveria.

O não fechamento da Rodada é, portanto, a hipótese que talvez mais convenha ao Brasil, pois daria ao novo Governo brasileiro a oportunidade para recolocar interesses que não se acham atendidos de maneira adequada no pacote delineado pelo Diretor Geral do GATT. Não é, aliás, impossível, que Clinton busque do seu Congresso um novo mandato negociador e proponha conseqüentemente nova prorrogação das negociaçóes da Rodada Uruguai, sem que isso possa ser entendido como deflagração de uma guerra comercial que colocaria em risco a sobrevivência do sistema multilateral de comércio.

A Clinton - mesmo que Bush consiga ainda fechar as negociaçóes agrícolas - pode muito bem interessar uma prorrogação da Rodada Uruguai que lhe permita incluir novas questôes que, tudo indica, the seriam caras. Os direitos dos trabalhadores e os novos padróes ambientais são matérias, por exemplo, que o Presidente eleito anunciou desejar introduzir no Acordo firmado por Bush com o México, que ainda pende de apreciação de forma global, sem possibilidade de emendas, pelo Congresso norte-americano. Este é, aliás, o mesmo procedimento de urgência ( fast track) previsto para consideração dos resultados da Rodada Uruguai. 


\title{
Resumo
}

A Rodada Uruguai não trata, como as anteriores, apenas de comércio de mercadorias, área onde pela primeira vez se vislumbra a possibilidade de liberalizaçáo em produtos agrícolas; dispóe também sobre serviços, propriedade intelectual e investimento. Mas não é certo que a Rodada se concluirá até o fim do ano, ou que seus eventuais resultados sejam automaticamente aceitos nos EUA, pela nova Administração ou pelo novo Congresso. Poderá ocorrer mais uma prorrogação da Rodada sem eclosão de uma guerra comercial entre os EUA e a CEE e o colapso do sistema multilateral de comércio. $O$ fechamento das negociaçóes agora, como resultado de um acordo entre os EUA e a CEE sobre subsídios à agricultura, pode ter implicaçōes sérias para o Brasil cujos interesses não estão adequadamente atendidos no pacote proposto pelo Diretor Geral do GATT, em especial no que se relaciona com os novos temas.

\begin{abstract}
The Uruguay Round, different from previous GATT rounds, does not deal only with trade in goods, where there seems to be, for the first time, the possibility of liberalization in agricultural products; it deals also with the new themes of trade in services, intelectual property and investment. It does nor seem assured that the ongoing round will be concluded by the end of this year; or that the its eventual results would be automatically accepted in the US, by the new Administration or the nes Congress. A prolongation of the talks, which is not to be excluded, will not necessarily imply a trade war between the US and the EEC, or the colapse of the multilateral system of trade. The conclusion of the talks now, as the result of a last minute agreement on agriculture between the US and the EEC, may have serious implications for Brazil whose interests have not been adequately taken care of in the final package proposed by the GATT Director-General, specially as regards the now thomes.
\end{abstract}

Paulo Nogueira Batista é diplomata c ex-embaixador do Brasil junto ao GATT (1983-87) e junto à Organizaçăo das Naçōes Unidas (ONU) (1989/90). É professor visitante da Área de Assuntos Internacionais do IEA.

Palestra feita pelo autor em 4 de norembro de 1992, no IEA. 